\title{
Artes da Existência: Foucault, a Psicanálise e as Práticas Clínicas
}

\author{
João Leite Ferreira Neto ${ }^{1}$ \\ Pontifícia Universidade Católica de Minas Gerais
}

\begin{abstract}
RESUMO - Este artigo se propõe a desenvolver um estudo conceitual dos diversos enfoques presentes na obra de Foucault para o estudo das práticas clínicas. Foucault mantém a preocupação de distinguir, a todo tempo, a análise dos vetores de dominação e dos vetores de liberação em suas diferentes formas conceituais. Mostra-se cético em relação ao potencial liberador das práticas clínicas, ainda que admita que possam manter "certa autonomia". A amplitude do conceito de artes da existência ultrapassa o campo das práticas clínicas, estrito senso, e pode englobar todo um conjunto de práticas psicossociais em curso hoje no país.
\end{abstract}

Palavras-chave: Foucault; psicanálise; psicologia clínica; intervenção psicossocial; processos de subjetivação.

\section{Arts of Existence: Foucault, Psychoanalysis, and Clinical Practices}

\begin{abstract}
This article intends to develop a conceptual investigation of the different approaches that appear in Foucault's work for the study of clinical practices. Foucault is continuously worried about distinguishing the analysis of domination vectors and liberation vectors in their distinct conceptual forms. He shows himself skeptical in relation to the releasing potential of clinical practices, even though he admits that they can keep "some level of autonomy". The amplitude of the concept of arts of existence exceeds the field of clinical practices, in a strict sense, and can involve a whole set of current psychosocial practices in Brazil.
\end{abstract}

Key words: Foucault; psychoanalysis; clinical psychology; psychosocial intervention; subjectivation processes.

Este texto se propõe a construir um percurso teórico e conceitual para subsidiar pesquisas que se interessem em utilizar o approach foucaultiano para pensar as práticas clínicas no universo "psi”. Sua intenção é rastrear, na obra de Foucault, as referências e os enfoques que ela traz ao campo das práticas clínicas. Como um dos objetivos é localizar nessa obra as principais referências e postulados, o texto se estende nas citações diretas. Essa escolha tem a intenção de permitir que outros interessados possam refazer o percurso e reconstruí-lo de outras maneiras. Um desdobramento desse estudo será aproximar as contribuições de Foucault no campo das práticas clínicas com o campo das chamadas práticas psicossociais no âmbito das políticas públicas, em movimentos sociais e nas ações do terceiro setor, atualmente em curso no Brasil, a ser desenvolvido posteriormente.

Desde seu início de estudos na École Normale Supériere, Foucault se interessou muito pela Psicologia. Obteve sua licenciatura em Psicologia em 1949, o primeiro dos três títulos na área, estagiou no Hospital Psiquiátrico Sainte-Anne em 1951 e seu primeiro emprego foi como professor de Psicologia na Faculdade de Letras de Lille, em 1952. Apesar de crises emocionais constantes, nunca se decidiu por um tratamento clínico, mesmo com a indicação de seu professor Daniel Lagache. Apenas uma tentativa que dura três semanas e uma dúvida que o acompanha por mais tempo: "deve-se ou não ser psicanalisado?” (Eribon, 1990, p. 56).

1 Endereço: R. Planetoides 271/102, Santa Lúcia, Belo Horizonte, MG, Brasil 30360-440.E-mail: jleite.bhe@terra.com.br
Seu primeiro livro foi publicado em 1954, Doença Mental e Personalidade, em 1962 revisto, ampliado e renomeado de Doença Mental e Psicologia. Em sua primeira versão, faz uma apresentação da psicologia e da loucura segundo os conceitos de Binswanger e Pavlov. Na segunda versão, introduz os elementos de sua pesquisa de Doutorado, História da loucura, localizando a origem da psicologia no século XIX, quando a exclusão da loucura e sua interiorização na perspectiva da moral e da culpa possibilitaram "uma tomada sobre a loucura e através dela uma psicologia geral" (Foucault, 1984a, p. 85). Sua conclusão é que a psicologia nunca poderá dizer a verdade sobre a loucura, pois é esta que detém a verdade sobre a psicologia, e que somente a literatura trágica "promete ao homem que um dia ele poderá encontrar-se livre de toda psicologia para o grande afrontamento trágico com a loucura" (p. 86). A literatura trágica é tomada, em paralelo com a experiência da loucura, como a produção de uma experiência-limite transgressora em relação à obra, que a faz ir além dos limites estabelecidos, subvertendo os códigos instituídos da língua e acolhendo, nesse movimento, a positividade da desrazão (Machado, 2000). Essa é a primeira localização que Foucault faz em sua obra de um vetor de liberdade que se contrapõe aos processos de dominação.

Do interesse fervoroso pela psicologia à formulação da equação definida de que o retorno a uma relação trágica com a loucura representaria a destruição da própria psicologia, uma nova etapa foi inaugurada no pensamento de Foucault. E mais do que isso, se entendermos que Foucault se tornou um pensador autônomo tendo como marco inicial sua tese de 1961, percebemos que isso acarretou o início de um enfoque crítico em relação às práticas "psi”. 


\section{A História da Loucura}

Na História da loucura encontramos uma discussão sobre a origem e função das práticas "psi” que privilegia o estudo de Freud e da psicanálise. Existe uma vasta bibliografia que aborda a relação de Foucault com a psicanálise, na qual se destaca uma conferência de Jacques Derrida, com a qual dialogaremos de modo mais próximo. Ele considera que Foucault, nesse livro, hesita em classificar a psicanálise como uma psicologia (Derrida, Roudinesco, Ganguilhem \& Major, 1994), e essa hesitação é marcada no momento que importa diferenciar o específico da contribuição freudiana. Entretanto, ao observarmos um conjunto mais amplo de textos foucaultianos, encontramos várias referências que indicam que o filósofo considerava as práticas psicológicas, psicanalíticas, médicas, pedagógicas e até mesmo filosóficas como pertencentes a um mesmo campo, que posteriormente ele definirá como o das "artes da existência" ou das "técnicas de si".

Por exemplo, em 1957, Foucault define a psicanálise como uma forma de psicologia que valoriza o sentido (Foucault, 1999). Em 1965, numa entrevista a Alain Badiou sobre Psicologia e Filosofia, considera desnecessário definir a psicologia como uma ciência, mas a vê como uma prática cultural, tal como a filosofia (Foucault, 1999), além de abordar, em vários momentos, a própria psicanálise enquanto fala de psicologia, afirmando, por exemplo, que a descoberta do inconsciente "é realmente confisco, pela psicologia, da maioria dos domínios que cobriam as ciências humanas" (p. 202). No mesmo ano classifica a psicologia como uma medicina, uma terapêutica e também uma pedagogia. A presença, a primeira vista curiosa, da filosofia no campo das "práticas de si" deve-se ao fato de Foucault não dissociar filosofia de modo de vida. As artes da existência na Grécia antiga eram essencialmente práticas médicas e filosóficas. A filosofia nasce na Grécia caracterizada como expressão de um modo de vida, uma opção existencial, além de ser uma prática coletiva que compunha uma "escola" filosófica (Hadot, 1999). Somente na Idade Média surge a idéia da filosofia como atividade puramente teórica. Em suas pesquisas finais, Foucault demonstra a permanente associação entre filosofia, estilo de vida e cuidado de si (Foucault, 1984b).

Percebemos, portanto, que Foucault não atribui importância em estabelecer diferenciações entre essas diferentes práticas. A questão que de fato o acossa é em que medida essas práticas estão a serviço da dominação e até onde elas podem contribuir para construção de autonomia e liberdade. Liberdade, na concepção foucaultiana, designa a resistência aos sistemas de saber e poder por meio da invenção de "novas formas de subjetividade" (Foucault, 1995a, p. 239). E é exatamente esse duplo eixo que está estabelecido na História da loucura e que reaparecerá, em outro formato, na História da sexualidade.

Retornando à discussão do livro História da Loucura, vemos que, inicialmente, Foucault associa Freud a Nietzsche por ambos possibilitarem ao homem moderno encontrar, no fundo de si mesmo, o "ponto de contestação de toda a verda$d e$ " (Foucault, 1978, p. 159). Depois, afirma que "é preciso ser justo com Freud" destacando o valor da psicanálise ao retomar a loucura ao nível da linguagem e reconstituir um dos elementos essenciais de uma experiência silenciada pelo positivismo, reabrindo, no "pensamento médico", a possibilidade de um diálogo com a desrazão. Encerra declarando: "Na psicanálise, o que está em jogo não é a psicologia, mas, exatamente, uma experiência da desrazão que a psicologia no mundo moderno houve por bem ocultar" (p. 338). É exatamente nesse momento que Foucault diferencia a contribuição específica da psicanálise da função moralizante de silenciamento da loucura promovida pela psicologia. Aqui, Freud pertence ao grupo de Nietzsche e está distante de Pinel e do saber psicológico.

Contudo, como veremos a seguir, a relação liberadora da psicanálise com a loucura é, segundo Foucault, apenas uma possibilidade, jamais de fato realizada. A segunda dimensão da interpretação foucaultiana se apresenta na afirmação de que a prática psicanalítica reproduz o asilo e que, na verdade, existe uma continuidade da dominação que vai de Pinel a Freud. Foucault muda então as peças de lugar aproximando, na sequiência, Freud de Pinel e distanciando-o de Nietzsche. Observemos a construção desse movimento.

Havia, na era positivista de construção do asilo mental, quatro estruturas fundamentais que o tornavam não um livre "domínio de observação, de diagnóstico e de terapêutica", mas um lugar de dominação e exclusão (Foucault, 1978, p. 496): o silenciamento da loucura, seu reconhecimento pelo espelho, seu julgamento moral e, finalmente, a apoteose da personagem do médico, que se tornará a figura "essencial do asilo", quando este se transformará em um "espaço médico". Daí em diante o poder médico não cessará de crescer. Foucault considera que Freud levará até as últimas conseqüências esse processo, seguindo rigorosamente todos seus desdobramentos, e operando uma subversão apenas aparente. Por um lado, Freud desconstruiu as três primeiras estruturas do asilo: aboliu o silêncio, apagou a necessidade de reconhecimento da loucura por ela mesma, fez com que fossem desativadas as instâncias de condenação moral; por outro, explorou ao máximo a quarta estrutura que envolve a personagem do médico, trazendo sobre este "todos os poderes que estavam divididos na existência coletiva do asilo" (Foucault, 1978, p. 502). A conclusão de Foucault é definitiva: Freud transmitiu para o médico todas as estruturas que Pinel e Tuke haviam organizado no internamento. Por isso, mesmo tendo libertado o doente da existência asilar, o manteve atado ao que havia de mais essencial nessa existência, com os poderes do asilo agrupados nas mãos do terapeuta. Na situação analítica a alienação se torna desalienante somente porque por meio do médico o alienado se torna sujeito. Seu veredicto final:

O médico, enquanto figura alienante, continua a ser a chave da psicanálise. Talvez seja porque ela não suprimiu essa estrutura última, e por ter conduzido a ela todas as outras, que a psicanálise não pode e não poderá ouvir as vozes da desrazão, nem decifrar por eles mesmos os signos da insanidade (Foucault, 1978, p. 503).

À desrazão só restará sua manifestação nas obras como as de Hördelin, Nerval, Nietzsche ou Artaud, na qual sua força escapa a essas "alienações que curam". Apenas nas práticas artísticas, literárias e filosóficas a desrazão encontrará a liberdade de se fazer ouvir, pois a psicanálise apenas "revestiu 
o olhar absoluto do vigilante com a palavra indefinidamente monologada do vigiado - conservando assim a velha estrutura asilar do olhar não-recíproco, porém equilibrando-o, numa reciprocidade não simétrica, através da nova estrutura da linguagem sem resposta" (Foucault, 1978, p. 482).

No decorrer de sua produção posterior, Foucault retomará insistentemente e de modo pendular essa dupla possibilidade: ora as práticas "psi" hegemonicamente funcionando como práticas disciplinares de sujeição, ora essas mesmas práticas como portadoras de uma virtual liberação e invenção de outras modalidades de subjetivação. Da História da loucura em diante seu diálogo se dará preferencialmente com a psicanálise, e secundariamente com a psicologia, como dispositivo de referência para pensar o binômio sujeição/liberação na produção dos processos de subjetivação.

Em 1975, ao retornar à função da psicanálise de dar uma sobrevida às estruturas asilares, ao retirar o alienado para fora do espaço asilar e, ao mesmo tempo, constituir o poder médico como produtor da verdade da doença, Foucault desenvolve uma breve análise do dispositivo clínico, ressaltando suas três regras. A primeira é a regra do encontro privado: o dispositivo é organizado com base em um contrato "livre" entre o médico e o doente (Foucault, 1979). A segunda é a de limitação de todos os efeitos da relação apenas no que se refere ao discurso: a associação livre delimita um campo de acontecimentos reduzidos à sua dimensão discursiva (correlata à regra da liberdade discursiva). Finalmente, a regra do divã: o acontecimento importante é apenas o que se dá no lugar e na hora da sessão analítica, no qual o poder do médico é amplamente exercido.

Vemos portanto que, em sua interpretação da clínica psicanalítica, Foucault aponta três aspectos, ao mesmo tempo fundadores e problemáticos dessa prática. No primeiro, anuncia que a psicanálise tem por solo uma nova organização social, chamada por ele de "sociedade disciplinar", na qual o poder é exercido de modo difuso, descentrado e marcado não por proibições ou repressões, mas por estimulação e produção. E o discurso científico se apresenta como um dos principais elementos dessa modalidade de dominação não-repressiva, pela produção de discursos de verdade que capturam a adesão aparentemente espontânea das pessoas. Nesse sentido, o "contrato livre" não está apartado das relações de poder, mas é um de seus efeitos. No segundo, Foucault aponta para a regra técnica que estabelece a cena analítica: o paciente deve dizer tudo e nada fazer a não ser dizer. É a "cura pela palavra" que hipertrofia os poderes do campo da fala e da linguagem, de onde emanarão todos os benefícios do tratamento ${ }^{2}$. Finalmente, denuncia a supervalorização do espaço do tratamento como centro e origem dos efeitos importantes que advirão na vida do paciente. Recusa a perspectiva que a vida fora do divã só teria relevância e pertinência na proporção em que atravessasse a decantação promovida na sessão analítica.

2 O conceito de realidade psíquica como contraponto à realidade material, permite à psicanálise restringir seu foco ao campo da fala e da linguagem, na medida em que, essencialmente, é esta realidade que interessa à escuta analítica (Laplanche \& Pontalis, 1983).

\section{Da Arqueologia do Saber à Genealogia do Poder}

Em As palavras e as coisas, Foucault surge com uma inversão revendo a crítica feita em 1961 e dizendo que "(...) nem a hipnose, nem a alienação do doente na personagem fantasmática do médico são constitutivos da psicanálise (...) esta só pode desenvolver-se na violência calma de uma relação singular e da transferência que ela requer" (Foucault, 1987, p. 394). Aqui considera a psicanálise, junto com a etnologia, como saberes privilegiados da modernidade, por desenvolverem um perpétuo princípio de crítica e inquietude face ao conhecimento estabelecido. Também avalia a possibilidade de avanço da prática clínica, distinguindo a psicanálise da psiquiatria, e antecipa algumas das formulações de Deleuze e Guattari num viés mais positivo:

É por isso que a psicanálise encontra nesta loucura por excelência - a que os psiquiatras chamam de esquizofrenia -o seu íntimo, o seu mais invencível tormento (...) De sorte que a psicanálise 'reconhece-se aî', quando ela é colocada diante destas mesmas psicoses às quais, no entanto ela quase não tem acesso: como se a psicose expusesse numa iluminação cruel e oferecesse de um modo demasiado longínquo, mas justamente demasiado próximo, aquilo em cuja direção a análise deve lentamente caminhar (Foucault, 1987, pp. 392-393).

As palavras e as coisas é, sem dúvida, o livro em que sua apreciação da psicanálise é mais receptiva, se tornando até mesmo um componente de seu procedimento de investigação de uma arqueologia das ciências do homem. Essa proximidade antecede o período no qual sua avaliação da psicanálise é mais impiedosa e iconoclasta, o da genealogia do poder que ele desenvolverá a partir dos anos 1970.

O primeiro volume da História da sexualidade: a vontade de saber, publicado em 1976, se apresenta como uma "arqueologia da psicanálise" realizada pelo estudo da história do dispositivo da sexualidade (Foucault, 1988, p. 122). Nele a psicanálise torna-se alvo. Foucault ataca a "hipótese repressiva" segundo a qual o século XVII seria o início de uma época de repressão sexual própria das sociedades burguesas, que se estenderia até à contribuição liberalizante de Freud. Ao contrário disso, nos últimos três séculos houve uma verdadeira explosão discursiva em torno do sexo, "uma incitação ao discurso, regulada e polimorfa" (p. 35). O gênio de Freud consistiu em "relançar com admirável eficácia, digna dos maiores espirituais da época clássica, a injunção secular de conhecer o sexo e coloca-lo em discurso" (p. 149). E, por meio dessa articulação entre sexo e discurso, construir uma técnica terapêutica para "eliminar os efeitos da interdição lá onde seu rigor a torne patogênica (...) naqueles que estão em condições de recorrer a ela" (p. 121).

A confissão medieval é entendida como a matriz geral da produção da discursividade sobre o sexo, que paulatinamente se expandiu e generalizou-se em variadas modalidades, entre as quais a sessão analítica é uma de suas versões mais recentes. Entre a confissão e a interpretação psicanalítica, na operação de valorizar o sexo e colocá-lo em discurso, existe uma linha de continuidade. A ruptura promovida pela psicanálise foi retomar o projeto de uma tecnologia médica 
própria do sexo, liberando-a da teoria da degenerescência e de "suas relações com a hereditariedade, e, portanto, com todos os racismos e eugenismos" (pp. 112-113). No mais, ela apenas leva ao pé da letra o que estava inscrito "na medicina e na psiquiatria do século XIX (...) trata-se certamente de sexualidade". Foucault entende que a descoberta mais importante da psicanálise "não é a teoria do desenvolvimento, não é o segredo sexual atrás das neuroses e das psicoses, é uma lógica do inconsciente" (Foucault, 1979, p. 261).

Após percorremos algumas das referências à psicanálise realizadas por Foucault, resta-nos perguntar o porquê de sua crítica ético-política à psicanálise feita em 1961 é atenuada em 1966 e acrescida da afirmação de que a mesma ocupa uma posição crítica de destaque entre as ciências do homem. E por que nove anos depois de seu contundente enaltecimento da psicanálise Foucault recupera sua interpretação sobre a dimensão de poder inerente à clínica psicanalítica, além de publicar, no ano seguinte, um livro no qual a psicanálise comparece como sparring? Antes de estendermos esse percurso em outras direções é relevante construir uma hipótese inicial do que se passou.

A genealogia conduz uma análise das condições políticas da emergência dos saberes. O poder se apresenta como uma segunda instância acoplada ao saber e que o produz. Aqui, a gênese do saber se apresenta inerente às relações de poder - $\mathrm{a}$ análise da sociedade disciplinar, que tem como objetivo tornar os corpos úteis e dóceis, se apresenta. Seu foco se desloca de um "método" (arqueologia) de análise da emergência dos saberes para uma "tática" (Foucault, 1979, p. 172) de resistência aos poderes hegemônicos.

Esse deslocamento traz profundas repercussões na obra e mesmo na vida de Foucault. Cresce em sua obra a influência de Nietzsche, de cuja obra ele retira a noção de genealogia. Além disso, essa nova compreensão da vida social atravessada pelas relações de poder conduz Foucault, pessoalmente, a assumir posições cada vez mais públicas fora do âmbito acadêmico. A partir dos anos 1970, e cada vez mais, Foucault se torna uma figura pública. Seu movimento inicial, em 1971, foi fundar e coordenar o GIP - Grupo de Informação sobre as Prisões, com o objetivo de permitir que "os prisioneiros possam dizer o que é intolerável no sistema de repressão penal" (Eribon, 1990, p. 211). Na seqüência, Foucault publica um de seus mais belos livros, Vigiar e punir, um livro contendo uma densa pesquisa histórica, mas que ele define como uma "história do presente". A associação entre pesquisa e vida se revela biograficamente como uma evidência.

Nesse momento, existia na França uma posição de fascínio e subordinação em relação à psicanálise, "onde a intelligentsia, por seu lugar na pirâmide e na hierarquia dos valores aceitos, concede à psicanálise um privilégio absoluto, que ninguém pode evitar" (Foucault, 1979, p. 267) ${ }^{3}$. Assim, a hegemonia da psicanálise na França se apresenta a Foucault como objeto de enfrentamento. Ele reprova a pretensão de se fazer da psicanálise ou do marxismo uma ciência, pois antes de buscar saber

3 Ainda que ele pense o poder como uma rede de relações plurais e capilarizadas cuja resistência também é plural, pontual e transitória (Foucault, 1987), ele assume também um embate mais frontal contra os poderes mais hegemônicos e centralizados. se a psicanálise pode ser científica, importa "interrogar sobre a ambição de poder que a pretensão de ser uma ciência traz. consigo (...) Qual vanguarda teórico-política vocês querem entronizar para separá-la de todas as numerosas, circundantes e descontínuas formas de saber" (Foucault, 1979, p. 172).

Cabe aqui retomar a queixa levantada por Derrida das referências feitas por Foucault à psicanálise e a Freud quase sempre ter um cunho generalizante, quando na verdade a psicanálise não é uma entidade coesa e monolítica, mas "seriam identidades bastante duvidosas, bastante divididas dentro delas mesmas" (Derrida \& cols., 1994, p. 87). Se essa acusação encontra sua realidade nos livros publicados, nas entrevistas concedidas por Foucault, a psicanálise é apresentada como portadora de uma face mais plural. Em entrevista de 1975, Foucault cita o exemplo do Brasil onde, na época, "a psicanálise desempenhava um papel político positivo de denúncia da cumplicidade entre os psiquiatras e o poder" (Foucault, 1979, p. 150), enquanto em países do leste europeu são os psiquiatras mais disciplinados que se interessam pela psicanálise. E conclui dizendo que a psicanálise "em algumas de suas atuações" produz efeitos de controle e normalização e em outras de inovação e resistência ao poder. Portanto, mesmo num momento histórico em que a psicanálise se apresentava como inimigo a ser combatido e denunciado, Foucault nunca renunciou por completo à tarefa de sustentar uma análise das descontinuidades histórico-sociais de onde e como a psicanálise se apresentava, traçando uma avaliação permeada por essas diferenças. Assim, não haveria rigorosamente como falar da psicanálise como um bloco homogêneo, mas o melhor seria acompanhar genealogicamente suas variadas inserções e modos de atuação.

Eribon (1996) escreveu um capítulo esclarecedor sobre as relações de Foucault com o estruturalismo e com Lacan. Remeto a ele a discussão sempre recorrente da presença ou ausência do estruturalismo na obra de Foucault, com a intenção de me ater ao mais específico que interessa a este artigo: em que as formulações da psicanálise mais interessavam a Foucault? A resposta de Eribon é que a Foucault interessava "o problema do sujeito". Em entrevista de 1978, Foucault declarou:

O sujeito não é a forma fundamental e originária, mas forma-se a partir de um certo número de processos (...) O sujeito tem uma gênese, o sujeito não é originário. Ora, quem disse isso? Freud, certamente, mas foi preciso que Lacan o mostrasse claramente. Daí a importância de Lacan (citado por Eribon, 1996, p. 147).

Em outro trabalho, explorei com mais detalhe a concepção foucaultiana da subjetividade como acontecimento histórico e sua aproximação e distanciamento das formulações psicanalíticas (Ferreira Neto, 2004). De como ele se alia à psicanálise no combate contra uma filosofia do sujeito da consciência e o tradicional enfoque de pensar o sujeito como subjectus, aquilo que subjaz fundamento e de como ele se afasta dela ao recusar a gênese do sujeito restrita ao campo da linguagem. A Foucault interessa o estudo das práticas reais, historicamente analisáveis que não podem ser reduzidas a uma onipresente "ordem simbólica". E é exatamente esse tema, o dos processos de subjetivação, que irá ocupar 
os interesses de Foucault em seus últimos anos de produção e existência.

\section{A Genealogia do Sujeito de Desejo}

Na década de 1980, Foucault formulou o último eixo de sua pesquisa. Entendia então que não era mais suficiente o estudo das formações de saberes e das relações de poder, pois o sistema de saberes e poderes produziam, também, subjetivação. Isso já se colocava em suas pesquisas anteriores de modo implícito, mas não diretamente problematizado. Havia sim o louco "psiquiatrizado" na História da loucura, o delinqüente disciplinado em Vigiar e punir e o sujeito da sexualidade da História da sexualidade I, mas apenas essa indicação não era suficiente. Fazia-se necessário explicitar a correlação imanente aos três eixos: saber, poder e subjetivação.

No eixo da subjetivação Foucault conseguirá, afinal, formular com precisão a inquietação que o acompanhou desde o início de seu trabalho: onde localizar o lugar do enfrentamento aos sujeitamentos promovidos pelas práticas de dominação? O que no primeiro eixo ele localizou na literatura, na filosofia e na arte (Hördelin, Nerval, Nietzsche, Artaud, etc.), no segundo eixo ele localizou nas "resistências" (o outro do poder e seu "interlocutor irredutível"), no terceiro eixo ele consegue demarcar de modo mais operacional com o conceito de subjetivação (verbete resistência: Revel, 2005).

Em primeiro lugar, não há um sujeito soberano, fundador, uma forma universal de sujeito que se encontra em qualquer lugar. Eu sou muito cético e muito hostil para com essa concepção de sujeito. Penso, ao contrário, que o sujeito se constitui por meio das práticas de assujeitamento ou de uma maneira mais autônoma, através das práticas de liberação, de liberdade, como na Antigüidade, desde, obviamente, um certo número de regras, estilos, convenções que se encontram no meio cultural (Foucault, 1994, p. 733).

Ou seja, os sistemas de saber/poder não produzem apenas subjetividades disciplinadas e submetidas. Foucault encontra nos gregos a invenção política de uma subjetivação ética e estética do governo voluntário de si mesmo por homens livres. "A subjetivação é uma operação artista que se distingue do saber e do poder, e não tem lugar no interior deles" (Deleuze, 1992, p. 140). Digo voluntário não sem certas precauções. Uma interpretação reiterada desse momento final de Foucault é que ele teria finalmente se rendido à noção do homem como sujeito dotado de "livre-arbítrio", recaindo no humanismo que sempre combateu (Billouet, 2003). Penso que essa interpretação ignora, pelo menos, dois fatores. O primeiro deles é que, como vimos anteriormente, a concepção de sujeito em Foucault é pós-psicanalítica - compartilha com a psicanálise o fato de a subjetividade ser pensada como um efeito, uma produção, e se afasta dela ao ampliar para o conjunto das práticas sociais discursivas e não-discursivas sua constituição. Como corretamente aponta Deleuze ao analisar sua obra, "Não há sujeito [na concepção humanista], mas uma produção de subjetividade: a subjetividade deve ser produzida, quando chega o momento, justamente porque não há sujeito" (Deleuze, 1992, p. 141). O segundo é que Foucault aponta com clareza que o submetimento voluntário dos gregos ao governo de si era essencialmente uma prática social dos cidadãos gregos, não uma decisão atomizada que o "livre-arbítrio" de um indivíduo particular decidia por fazer. Como lembra Fréderic Gros, as práticas de si são exercidas num contexto "comunitário e institucional" (Gros, 2006, p. 131). Em suma, a afirmativa feita por Billouet, entre outros, de uma suposta recaída de Foucault na concepção de um sujeito individual livre é apressada e parcial. Em última instância, ainda que este, ocasionalmente utilize a expressão “sujeito", o que é visado, de fato, é a subjetivação conquanto processo.

Em sua última entrevista, pouco antes de sua morte, cuja transcrição não foi por ele revisada (Daniel Defert recebeu essa incumbência), encontramos a seguinte pergunta:

\footnotetext{
- Este sujeito é, para o senhor, condição de possibilidade de uma experiência?

- De forma alguma. É a experiência, que é a racionalização de um processo ele mesmo provisório, que redunda em um sujeito, ou melhor, em sujeitos. Eu chamaria de subjetivação o processo pelo qual se obtém a constituição de um sujeito, mais precisamente de uma subjetividade (Foucault, 2004, p. 262).
}

Com base nesse terceiro eixo, Foucault refaz seu projeto de pesquisa de uma história da sexualidade. Importa agora investigar a sexualidade conquanto experiência, definindo experiência como resultante da correlação entre os eixos do saber, do poder e da subjetividade. Por essa razão, interessalhe agora uma história geral das técnicas de si, dos modos de subjetivação e de como as "artes da existência" inventadas pelos gregos percorreram a história do Ocidente e se transformaram. Uma observação merece ser transcrita: "Essas 'artes de existência', essas 'técnicas de si', perderam, sem dúvida, uma parte de sua autonomia quando, foram integradas no exercício de um poder pastoral e, mais tarde, em práticas de tipo educativo, médico ou psicológico" (Foucault, 1984b, p. 15). Novamente, a posição de Foucault é mais cética em relação às práticas clínicas, mas sem fechar a possibilidade de que as práticas médicas e psicológicas possam ainda produzir certa autonomia ou liberação. Esse ceticismo pode ser ilustrado tomando-se, mais uma vez, a psicanálise como exemplo. Foucault a define como sendo "uma técnica de trabalho de si sobre si, fundada na confissão. Nesse sentido, é igualmente uma técnica de controle" (Foucault, 1999, p. 310). Afirma que, mesmo assim, ela pode ajudar as pessoas, desde que o cliente confira credibilidade à prática, tal como ocorre com o xamanismo nas sociedades primitivas. Em ambos os casos isso que acarreta o estabelecimento de relações de poder marcadas por certa hierarquização.

Sua maior crítica, a essa altura, decorre do fato de a psicologia e a psicanálise se apresentarem como portadoras de um discurso verdadeiro/científico "do que é о eи, do que é o desejo, do que é o inconsciente" (Foucault, 1995b, p. 255). Tal posição só tenderá a produzir um modo de subjetivação disciplinado, assujeitado. Na verdade, o que mais importa não é o conhecimento de si mesmo, mas a invenção de si mesmo, a ruptura com uma subjetividade identitária em função de uma subjetivação que "desprende-se de si mesma" e cria um devir outro (Ferreira Neto, 2004). Em resumo, Foucault define o campo das asceses modernas e leigas como um conjunto 
de práticas clínicas médicas, psicológicas, psicanalíticas e filosóficas, que podem produzir processos de assujeitamento e/ou liberação.

Em outro trabalho (Ferreira Neto \& Penna, 2004), desenvolvi aproximações entre a noção de ética como ascese e prática de liberdade presente nos últimos trabalhos de Foucault e a ética da psicanálise proposta por Lacan, por este chamada de "a ascese freudiana" (Lacan, 1988, p. 16). As aproximações entre Foucault e Lacan são, em alguns momentos, convergentes (Rajchman, 1993) e seus interesses de pesquisa encontravam ressonância. A idéia daquele trabalho era, em associação com outros estudos (Figueiredo, 1995; Rolnik, 1995), pensar as práticas clínicas do campo "psi" como "técnicas de si" modernas e definir sua aferição mais no campo da ética que no campo da epistemologia. Portanto, avaliar se caminham na direção de práticas de normalização ou na de práticas inventivas e liberadoras. Penso que esse é, também, um importante tema de pesquisa para os que se interessam pela investigação das práticas clínicas.

\section{Algumas Hipóteses Finais}

Considerando o conjunto de suas obras, a avaliação de Foucault do campo das práticas clínicas psicológicas, psicanalíticas ou médicas possui, na maioria das vezes, a direção de entendê-las como práticas disciplinares, e sua possibilidade de autonomia se configura mais como exceção que regra. A psicanálise se constitui uma figura particular. Apesar de Foucault, em geral, considerá-la como pertencente ao mesmo campo das práticas psicológicas, médicas e filosóficas, seu intercâmbio com ela ocupou um lugar significativo em sua obra. Podemos entender que Foucault a tomou como a mais instigante das práticas clínicas e a incorporou, mesmo que de modo crítico e parcial, ao corpo de algumas de suas próprias formulações. Entretanto, ele encontra também na psicanálise alguns dos impasses próprios das demais práticas clínicas. Em particular o que se refere à posição transferencial dirigida à figura do analista, o gestor último do tratamento, ao qual se sujeita o indivíduo que "livremente" busca o tratamento. A situação analítica comporta uma relação hierarquizada de poder que lhe é constitutiva. Essa crítica coincide, em parte, com a de Guattari, quando este denuncia o fato do inconsciente ser considerado um domínio exclusivo de especialistas e que somente estes poderiam conduzir essa prática "que exige muito tempo e requer o estabelecimento de um dispositivo muito particular" (Guattari, 1981, p. 166). Seria possível a produção da autonomia a partir de uma relação de saber/poder estabelecida com outro? A suspeita de Foucault é que uma situação organizada a partir de elementos de saber/poder tem um potencial reduzido para produzir processos de autonomia. Produzir subjetivação inventiva a partir de uma fala endereçada ao outro para, no final do tratamento, prescindir desse outro, é uma contradição cuja superação não é tão simples quanto a psicanálise e as psicoterapias tendem a supor.

No que diz respeito às práticas clínicas, psicanalíticas ou não, podemos incluí-las no campo que Foucault denominou "artes da existência", "asceses", ou "práticas de si”. Existe uma tradição que, no Ocidente se inicia com os gregos, passa pelo cristianismo e culmina nas asceses leigas da modernidade - uma das quais é a clínica “psi”. Essa é um dispositivo técnico particular que faz parte de um conjunto historicamente extenso de tecnologias de si, cuja variação é bem mais extensa. Curiosamente, numa em época em que surgem novas modalidades de práticas psicossociais, técnicas ou populares com efeitos significativos em indivíduos e comunidades, fica claro que as "artes da existência" não podem se restringir ao que hodiernamente chamamos de clínica. Estou me referindo às oficinas para portadores de sofrimento mental em Centros de Convivência, aos programas de abordagem aos moradores de rua em algumas metrópoles brasileiras, aos vigorosos movimentos sociais de base popular, aos diversos projetos sociais em curso pelo país afora. Nesses casos, como em vários outros, independentemente de possuírem um aporte clínico, estrito senso ou não, é inegável seu caráter de "práticas de si” coletivas, algumas portadoras de uma dimensão criativa e emancipatória ${ }^{4}$, em que a presença ou não de especialistas não é o que define seu mérito ou alcance. Em suma, a clínica, estrito senso, seria um dispositivo participante de um conjunto bem mais diversificado e heterogêneo de "práticas de si", produzindo nesse fazer novos processos de subjetivação. E não há razão aparente alguma que nos leve a considerar a prática clínica num patamar superior às outras "artes da existência". E muito mais importante que fazer uma investigação nessas novas práticas psicossociais no que elas têm de clínico, é avaliar o quanto trazem de invenção na construção de subjetivações individuais e coletivas autônomas, tomando sua dimensão ético-política como crivo dessa avaliação.

Finalmente, o desenvolvimento de "artes da existência" num viés liberador deve ir além da operação de um dispositivo técnico delimitado tal como o setting clínico. As artes da existência são práticas de vida individual e coletiva em que não se dissociam práticas de subjetivação e práticas sociopolíticas, ações individuais e ações sociais. Podemos entender como exemplo, que uma "prática de si” no âmbito da saúde pública, numa perspectiva foucaultiana, pensará a intervenção técnica e profissional como secundária à produção de processos de subjetivação autônomos, sem considerar como necessária a mediação técnica de um profissional "psi”.

\section{Referências}

Billouet, P. (2003). Foucault (B. Sidou, Trad.). São Paulo: Estação Liberdade.

Deleuze, G. (1992). Conversações (P. Pelbart, Trad.). Rio de Janeiro: Ed. 34.

Derrida, J., Roudinesco, E., Ganguilhem, G. \& Major, R. (1994). Foucault: leituras da história da loucura. Rio de Janeiro: Relume-Dumará.

Eribon, D. (1990). Michel Foucault, 1926-1984 (H. Feist., Trad.). São Paulo: Companhia da Letras.

Eribon, D. (1996). Michel Foucault e seus contemporâneos (L. Magalhães, Trad.). Rio de Janeiro: Jorge Zahar.

4 Digo criativo e emancipatório como um efeito possível, não necessário, dessas práticas. Na perspectiva foucaultiana, nada garante, antecipadamente, a eficácia ético-política de uma prática qualquer. 
Ferreira Neto, J. L. (2004). A formação do psicólogo: clínica, social e mercado. São Paulo: Escuta; Belo Horizonte: Fumec.

Ferreira Neto, J. L. \& Penna, L. M. D. M. (2004). Ética, clínica e subjetivação em Lacan e Foucault: considerações iniciais. Psico, 35(2), 207-212.

Figueiredo, L. C. (1995). Revisitando as Psicologias: da Epistemologia à Ética nas práticas e discursos psicológicos. São Paulo: Educ; Petrópolis: Vozes.

Foucault, M. (1978). História da loucura (J. Coelho, Trad.). São Paulo: Perspectiva.

Foucault, M. (1979). Microfísica do poder (R. Machado, Trad.). Rio de Janeiro: Graal.

Foucault, M. (1984a). Doença Mental e Psicologia (L. Shalders, Trad.). Rio de Janeiro: Tempo Brasileiro.

Foucault, M. (1984b). História da sexualidade 2: o uso dos prazeres (M. Albuquerque \& J. Albuquerque, Trad.). Rio de Janeiro: Graal.

Foucault, M. (1987). As palavras e as coisas (4ª ed., S. Muchail, Trad.). São Paulo: Martins Fontes.

Foucault, M. (1988). História da sexualidade 1: a vontade de saber ( $7^{\text {a }}$ ed., M. Albuquerque \& J. Albuquerque, Trad.). Rio de Janeiro: Graal.

Foucault, M. (1994). Dits et écrits IV. Paris: Gallimard.

Foucault, M. (1995a). O sujeito e o poder. Em H. Rabinow \& P. Dreyfus (Orgs.), Michel Foucault: uma trajetória filosófica (V. Carrero, Trad., pp. 231-249). Rio de Janeiro: Forense Universitária.

Foucault, M. (1995b). Sobre a genealogia da ética: uma revisão do trabalho. Em H. Rabinow \& P. Dreyfus (Orgs.), Michel Foucault: uma trajetória filosófica (M. Albuquerque \& J. Albuquerque, Trad., pp. 253-291) Rio de Janeiro: Forense Universitária.
Foucault, M. (1999). Michel Foucault. Problematização do sujeito: Psicologia, Psiquiatria e Psicanálise. (V. Ribeiro, Trad.). Rio de Janeiro: Forense Universitária.

Foucault, M. (2004). Ditos e escritos V. Ética, sexualidade, política (E. Monteiro \& L. D. Barbosa, Trad.). Rio de Janeiro: Forense Universitária.

Gros, F. (2006). O cuidado de si em Michel Foucault. Em M.Rago $\&$ A. Veiga-Neto (Orgs.), Figuras de Foucault (pp. 127-138). Belo Horizonte: Autêntica.

Guattari, F. (1981). Revolução molecular: pulsações políticas do desejo (S. Rolnik, Trad.). São Paulo: Brasiliense.

Hadot, P. (1999). O que é a filosofia antiga? (D. Macedo, Trad.). São Paulo: Loyola.

Lacan, J. (1988). O Seminário. Livro 7. A ética da psicanálise (A. Quinet, Trad.). Rio de Janeiro: Zahar.

Laplanche, J. \& Pontalis, J. B. (1983). Vocabulário de Psicanálise ( $7^{\text {a }}$ ed., P. Tamen, Trad.). São Paulo: Martins Fontes.

Machado, R. (2000). Foucault, a filosofia e a literatura. Rio de Janeiro: Jorge Zahar.

Rajchman, J. (1993). Eros e verdade: Lacan, Foucault e a questão da ética (V. Ribeiro, Trad.). Rio de Janeiro: J. Zahar.

Revel, J. (2005). Foucault: conceitos essenciais (M. G. Gregolim, Trad.). São Carlos: Claraluz.

Rolnik, S. (1995). Subjetividade, ética e cultura nas práticas clínicas. Cadernos de Subjetividade, 3(2), 305-313.

Recebido em 26.10.2005

Primeira decisão editorial em 17.04.2006

Versão final em 17.05.2006

Aceito em 29.03.2007

\section{ENCONTRO DE PSICOTERAPIA E MEDICINA COMPORTAMENTAL - ABPMC}

Local: Hotel Nacional - Brasília/DF

Período: 27 a 30 de setembro de 2007

Realização:

Sociedade Brasileira de Psicoterapia e Medicina Comportamental

Informações e inscrição:

www.abpmc.org.br

abpmc@abpmc.org.br

(61) 3244.5442 